\title{
Sequential Thalamic Hemorrhage and Ischaemia in the Percheron Artery Territory
}

\author{
Conrado J. Estol ${ }^{1}$, Ricardo Mora ${ }^{2}$, María de la Paz Chang ${ }^{3}$, Manuel Vincenti ${ }^{3}$ and Marcelo Costilla ${ }^{3}$ \\ ${ }^{1}$ Director, Medicina de Corazón y Cerebro-MECyC-, Director, Stroke Unit, Sanatorio Güemes, Av. Callao 875 3ro. F, City of Buenos Aires, Argentina \\ ${ }^{2}$ Neurology Resident, Sanatorio Güemes, City of Buenos Aires, Argentina \\ ${ }^{3}$ Intensivist, Stroke Unit Sanatorio Güemes, City of Buenos Aires, Argentina
}

Correspondence to:

Ricardo Mora

Neurology Resident, Sanatorio Güemes

City of Buenos Aires, Argentina

Tel: (+5411) 26587689

E-mail: remch82@gmail.com

Received: May 01, 2019

Accepted: July 22, 2019

Published: July 23, 2019

Citation: Estol CJ, Mora R, de la Paz Chang M, Vincenti M, Costilla M.2019. Sequential Thalamic Hemorrhage and Ischaemia in the Percheron Artery Territory. J Neuroimaging Psychiatry Neurol 4(1): 15-16.

Copyright: (C) 2019 Estol et al. This is an Open Access article distributed under the terms of the Creative Commons Attribution 4.0 International License (CC-BY) (http://creativecommons. org/licenses/by/4.0/) which permits commercial use, including reproduction, adaptation, and distribution of the article provided the original author and source are credited.

Published by United Scientific Group

\section{Abstract}

Bilateral thalamic ischemia and hemorrhages are unusual [1-5]. They almost exclusively affect the posterior paramedian thalamic region supplied by the artery of Percheron and rarely the anterior polar artery territory causing a variety of cognitive, arousal and personality deficits [6].

To our knowledge, we report the first patient who had the unusual presentation of a left paramedian hypertensive thalamic hemorrhage followed within three days by a right paramedian thalamic infarction.

\section{Keywords}

Hypertension, Hemorrhagic

\section{Case Report}

An 84-year-old woman was found with an altered mental status and right hemiparesis. She had CHF, hypertension and hyperlipidemia under adequate pharmacologic treatment. An initial CT (Figure 1A) showed a left paramedian thalamic hemorrhage with mass effect over the third ventricle (arrow). Her blood pressure on admission was 190/100 $\mathrm{mmHg}$ requiring IV labetalol and sodium nitroprusside for control. Her EKG revealed AF and the general laboratory results were normal including sed rate. Transcranial doppler results did not reveal abnormal velocities suggestive of stenosis in the posterior circulation. At $72 \mathrm{hrs}$ from admission her mental status deteriorated and a new CT (Figure 1B) did not show hydrocephalus or significant changes in the hemorrhage although a new hypodensity was observed in the right paramedian thalamic territory. On

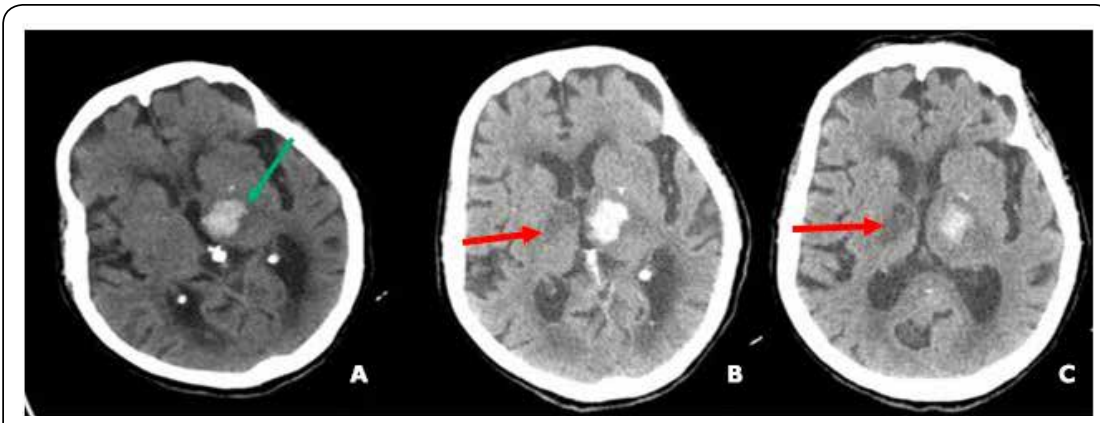

Figure 1: $\mathrm{CT}$ evolution over a week showing the left thalamic hemorrhage (green arrow in figure A) and a right thalamic infarction (red arrows in figures B and C). 
day 5, she did not follow commands, her speech was severely dysarthric and weakness on the right became more severe. A CT (Figure 1C) confirmed the infarction on the right paramedian thalamic territory. On day 7 the patient was stuporous, was intubated and died $24 \mathrm{hrs}$ later.

Hemorrhagic vascular thalamic lesions occur most commonly in the lateral thalamo-geniculate artery territory (75.9\%) followed by the paramedian (15.5\%), posterior choroidal (5.3\%) and the anterior polar artery (3.3\%) territories [7]. Thalamic hemorrhages are more common in elderly individuals with hypertension as was the case of our patient $[7,8]$. Bilateral thalamic hemorrhages have rarely been reported [4]. Bilateral thalamic ischemic vascular lesions have been reported as $0.6 \%$ of all infarctions [5]. Bilateral ischemia may occur because the artery of Percheron supplies the paramedian nuclei bilaterally in up to $12 \%$ of individuals $[1,2,9]$. At times, the anterior thalamic nuclei, usually supplied by the polar artery arising from the posterior communicating artery on each side, may receive their vascular supply from the Percheron artery or from a single polar artery explaining bilateral anterior paramedian infarctions [3]. A venous infarction would be unlikely in an 84-year-old without history of a hypercoagulable state and imaging is supportive of arterial territory rather than venous (more diffuse and with associated edema) compromise. Atrial fibrillation could cause small vessel disease; however, the CT was obtained within a few hours from stroke onset without allowing time for such a significant hemorrhagic transformation. Our patient had a left thalamic paramedian hemorrhage secondary to hypertension followed by an ischaemic stroke in the same vascular territory of the contralateral side. The left sided arteriolar branch of Percheron's artery likely developed a saccular CharcotBouchard aneurysm that ruptured causing a hemorrhage. We postulate as probable explanations of the exceptional scenario of hemorrhage and contralateral thalamic infarction that mass effect from the hemorrhage strangled the right sided Percheron's arteriole branches leading to infarction in that territory or alternatively that vasospasm occurred secondary to the presence of blood resulting in ischemia and infarction on the right.

\section{References}

1. Bogousslavsky J, Regli F, Uske A. 1988. Thalamic infarcts: clinical syndromes, etiology, and prognosis. Neurology 38(6): 837-848. https:// doi.org/10.1212/wnl.38.6.837

2. Garcia-Grimshaw M, Peschard-Franco M, Gutierrez-Manjarrez F. 2018. Bilateral thalamic ischemic stroke secondary to occlusion of the artery of percheron. Cureus 10(5): e2676. https://doi.org/10.7759/ cureus. 2676

3. Kaplan R, Estol CJ, Damasio H, Caplan LR. 1991. Bilateral polar artery thalamic infarcts. Neurology 41(suppl 1): 329.

4. Choudhary A, Goyal M, Singh R. 2018. Simultaneous bilateral hypertensive thalamic hemorrhage: a rare event. Neurol India 66(2): 575-577. https://doi.org/10.4103/0028-3886.227323

5. Kumral E, Evyapan D, Balkõr K, Kutluhan S. 2001. Bilateral thalamic infarction. Clinical, etiological and MRI correlates. Acta Neurol Scand 103(1): 35-42. https://doi.org/10.1034/j.1600-0404.2001.00141.x

6. Schmahmann J. 2003. Vascular syndromes of the thalamus. Stroke 34(9): 2264-2278. https://doi.org/10.1161/01.STR.0000087786.38997.9E

7. Teramoto S, Yamamoto T, Nakao Y, Watanabe M. 2017. Novel anatomic classification of spontaneous thalamic hemorrhage classified by vascular territory of thalamus. World Neurosurg 104: 452-458. https:// doi.org/10.1016/j.wneu.2017.05.059

8. Gotoh S, Hata J, Ninomiya T, Hirakawa Y, Nagata M, et al. 2014. Trends in the incidence and survival of intracerebral hemorrhage by its location in a Japanese community. Circ J 78(2): 403-409. https://doi. org/10.1253/circj.CJ-13-0811

9. Griessenauer CJ, Loukas M, Tubbs RS, Cohen-Gadol AA. 2014. The artery of Percheron: an anatomic study with potential neurosurgical and neuroendovascular importance. Br J Neurosurg 28(1): 81-85. https://doi. org/10.3109/02688697.2013.812181 